\begin{tabular}{|l|l|l||}
\hline \multicolumn{2}{|c|}{ PublisherInfo } \\
\hline \hline PublisherName & $:$ & BioMed Central \\
\hline \hline PublisherLocation & $:$ & London \\
\hline \hline PublisherImprintName & $:$ & BioMed Central \\
\hline \hline
\end{tabular}

\title{
MRSA spread in the ICU is related to nursing workload
}

\begin{tabular}{|l|l|l||}
\hline \multicolumn{2}{|c|}{ ArticleInfo } \\
\hline \hline ArticleID & $:$ & 4182 \\
\hline \hline ArticleDOI & $:$ & $10.1186 /$ ccf-2000-4008 \\
\hline \hline ArticleCitationID & $:$ & 4008 \\
\hline \hline ArticleSequenceNumber & $:$ & 41 \\
\hline \hline ArticleCategory & $:$ & Paper Report \\
\hline \hline ArticleFirstPage & $:$ & 1 \\
\hline \hline ArticleLastPage & $:$ & 3 \\
\hline \hline & & RegistrationDate : 2000-1-14 \\
\hline ArticleHistory & $:$ & OnlineDate \\
\hline \hline ArticleCopyright & $:$ & Current Science Ltd2000-1-14 \\
\hline \hline ArticleGrants & $:$ & \\
\hline \hline ArticleContext & $:$ & 1305422 \\
\hline \hline
\end{tabular}




\section{Keywords}

Intensive care, MRSA, nosocomial infection, nursing

\section{Comments}

This is an interesting idea for a study but I do not believe that the conclusions in the discussion are supported by the results as there are major problems with the methodology. Firstly, when mean, peak and trough levels of the indices are considered there are 26 possible correlations, of which 10 are reported as statistically significant. What conclusion is it safe to draw when, for example, the peak and trough staffing levels are weakly correlated with the number of MRSA cases but the mean staffing level apparently isn't? Secondly, there are fewer significant correlations of potential transmissions (three) than of actual cases (seven) with nurse staffing indices. Given the likely delay between the time of crossinfection and subsequent colonisation (sufficient to be detectable by surveillance swabs), this seems difficult to explain. Thirdly, and most importantly, the authors seem to have made the common error of confusing correlation with causation. It is interesting that MRSA cases and potential transmissions are raw figures - i.e. not related to the number of patients present. It is likely that nurse staffing indices will be most extreme when the ICU is full. MRSA cases and cases of potential transmission will clearly also be higher when there are more patients. (Similarly a 300-bedded hospital would expect fewer MRSA cases than a 1000-bedded hospital.) This is a plausible explanation for the weak correlations reported in the study.

\section{Introduction}

Methicillin resistant Staphylococcus aureus (MRSA) is a major infection problem in the intensive care unit (ICU) and may be related to nursing staff workload.

\section{Aims}

To investigate the relationship between nursing staff workload and MRSA outbreaks in the ICU. 


\section{Methods}

New cases of MRSA in a teaching hospital ICU were identified retrospectively. Various indices of nurse staffing level versus patient dependency were calculated for each day. Actual MRSA cases and potential MRSA transmission were calculated for each day. A potential MRSA transmission was defined as a patient who subsequently became MRSA positive provided there was another patient who was already MRSA positive (or who would become so) on the unit that day. Pearson's coefficient of correlation was calculated for the number of MRSA cases on the ward, and for the number of possible transmissions versus all indices of nursing staff level.

\section{Results}

There were weak (all less than 0.2) but statistically significant correlations for both actual MRSA cases and potential transmissions, with several indices of nurse staffing level.

\section{Discussion}

There is a dearth of published work on the role of staffing numbers in cross infection. An inadequate number of nursing staff contributes to the spread of nosocomial infection in ICUs.

\section{References}

1. Vicca AF: Nursing staff workload as a determinant of methicillin-resistant Staphylococcus aureusspread in an adult intensive care unit. J Hosp Infect. 1999, 43: 109-113.

This PDF file was created after publication. 